\title{
(6) OPEN ACCESS \\ Sexually transmitted infections and sexual behaviour of deploying shipboard US military personnel: a cross-sectional analysis
}

\author{
Judith Harbertson, ${ }^{1,2,3}$ Paul T Scott, ${ }^{1}$ John Moore, ${ }^{4}$ Michael Wolf, ${ }^{4}$ James Morris, ${ }^{4}$ \\ Scott Thrasher, ${ }^{4}$ Michael D'Onofrio, ${ }^{1}$ Michael P Grillo, ${ }^{3}$ Marni B Jacobs, ${ }^{3}$ \\ Bonnie R Tran, ${ }^{3}$ Jun Tian, ${ }^{1,2}$ Stanley I Ito, ${ }^{3}$ Jennifer McAnany, ${ }^{3}$ Nelson Michael, ${ }^{1}$ \\ Braden R Hale 3,5
}

- Additional material is published online only. To view please visit the journal online (http://dx.doi.org/10.1136/ sextrans-2015-052163).

For numbered affiliations see end of article.

\section{Correspondence to} Dr Judith Harbertson, US Military HIV Research Program, Naval Health Research Center, 140 Sylvester Road, San Diego, CA 92106, USA;

judith.harbertson.ctr@mail.mil

Received 16 May 2015 Revised 27 August 2015

Accepted 31 August 2015

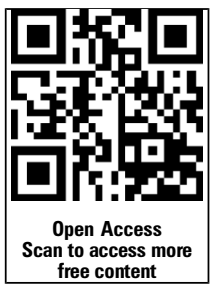

\section{SLinked}

- http://dx.doi.org/10.1136/ sextrans-2015-052017

- http://dx.doi.org/10.1136/ sextrans-2015-052256

\section{CrossMark}

To cite: Harbertson J,

Scott PT, Moore J, et al. Sex Transm Infect 2015;91: 581-588.

\section{ABSTRACT}

Objectives Sexually transmitted infection (STI) prevalence and risk behaviour may differ at different phases of deployment. We examined STI prevalence and sexual behaviour in the predeployment time period (12 months prior) among recently deployed shipboard US Navy and Marine Corps military personnel.

Methods Data were collected from 1938 male and 515 female service members through an anonymous, self-completed survey assessing sexual behaviours and STI acquisition characteristics in the past 12 months. Cross-sectional sex-stratified descriptive statistics are reported.

Results Overall, 67\% ( $n=1262 / 1896)$ reported last sex with a military beneficiary (spouse, $n=931$, non-spouse service member, $n=331$ ). Among those with a sexual partner outside their primary partnership, $24 \%$ ( $n=90 /$ 373) reported using a condom the last time they had sex and $30 \%(n=72 / 243)$ reported their outside partner was a service member. In total, $90 \%(n=210 / 233)$ reported acquiring their most recent STI in the USA (88\%, $n=126 / 143$ among those reporting $\geq 1$ deployments and an $\mathrm{STI} \geq 1$ year ago) and a significantly higher proportion $(p<0.01)$ of women than men acquired the STI from their regular partner ( $54 \%$ vs $21 \%$ ) and/or a service member (50\% vs 26\%).

Conclusions Findings suggest a complex sexual network among service members and military beneficiaries. Findings may extend to other mobile civilian and military populations. Data suggest most STI transmission within the shipboard community may occur in local versus foreign ports but analyses from later time points in deployment are needed. These data may inform more effective STI prevention interventions.

\section{INTRODUCTION}

Sexually transmitted infections (STIs) comprise approximately $75 \%$ of reportable infectious diseases within the US Department of Defense, reducing readiness, causing substantial reproductive morbidity, generating significant healthcare costs and causing lost personnel time. ${ }^{1-4}$ Scant data exist for changes in STI risk during a military deployment cycle, and previous data collected in the US Navy and US Marine Corps on STIs and sexual behaviours are limited. ${ }^{15-7}$ Furthermore, shipboard personnel are exempt from standardised predeployment and postdeployment health assessments administered to 'boots on the ground' land-based deploying personnel, thus limiting comprehensive population health assessments in this seagoing risk group.

The most recent STI study examining a deployed shipboard US Navy population focused on STI acquisition from sex workers during port visits ${ }^{8}$ and was conducted over 20 years ago when women were barred from deployments. Women now comprise approximately $17 \%$ of shipboard crews, the 'Don't Ask, Don't Tell' policy has been implemented and repealed ${ }^{9}{ }^{10}$ and internet-based social networking has expanded as a venue to meet sexual partners. ${ }^{11}$ Although the prevalence of STIs and STI risk factors vary by US military service branch, ${ }^{15}$ most data demonstrate both are elevated in US military personnel compared with civilians. $^{7} 1213$

The present study examines STI risk behaviours in the 12 months prior to deployment among an understudied but important US Navy and Marine Corps shipboard population. Gaining an understanding of the risk environment for deploying shipboard service members, and defining components of their sexual network and typical sexual risk behaviours will enable development of specific interventions to mitigate STI risk for shipboard personnel, and for other mobile military and civilian populations. Benefits specific to the US Navy and Marine Corps include increasing readiness and decreasing STI-related healthcare costs among service members and their beneficiaries.

\section{METHODS}

Study overview

From February 2012 through August 2014, data were collected for a longitudinal study designed to measure prevalence of self-reported STIs and associated sexual, alcohol use, mental health and lifestyle risk factors among active-duty deploying, shipboard US Navy and Marine Corps personnel at three different time points across the deployment cycle. An anonymous, voluntary, selfcompleted questionnaire was administered at (1) predeployment, within 2 weeks of departure from 


\section{Epidemiology}

Table 1 Demographics of active-duty deploying US Navy and Marine Corps respondents by sex

\begin{tabular}{|c|c|c|c|c|}
\hline Characteristic & $\begin{array}{l}\text { Total }(\mathrm{N}=2453) \\
\mathrm{N}(\%)\end{array}$ & $\begin{array}{l}\text { Men }(n=1938) \\
n(\%)\end{array}$ & $\begin{array}{l}\text { Women }(n=515) \\
n(\%)\end{array}$ & $p$ Value \\
\hline Age (years, $n=2453$ ) & & & & $<0.01$ \\
\hline $17-19$ & $125(5.1)$ & $92(4.8)$ & $33(6.4)$ & \\
\hline $20-24$ & $1148(46.8)$ & $883(45.6)$ & $265(51.5)$ & \\
\hline $25-29$ & $563(23.0)$ & $433(22.3)$ & $130(25.2)$ & \\
\hline $30-34$ & $296(12.1)$ & $257(13.3)$ & $39(7.6)$ & \\
\hline $35-39$ & $206(8.4)$ & $174(9.0)$ & $32(6.2)$ & \\
\hline $40+$ & $115(4.7)$ & $99(5.1)$ & $16(3.1)$ & \\
\hline Mean $\pm S D$, median & $26.4 \pm 6.6,24$ & $26.7 \pm 6.7,24$ & $25.3 \pm 6.2,24$ & $<0.01$ \\
\hline Range & $18-64$ & $18-63$ & 19-64 & \\
\hline Service branch ( $n=2435$ ) & & & & $<0.01$ \\
\hline Navy & $2043(83.9)$ & $1543(80.2)$ & $500(97.7)$ & \\
\hline Marine Corps & $392(16.1)$ & $380(19.8)$ & $12(2.3)$ & \\
\hline Military rank ( $n=2433)$ & & & & $<0.01$ \\
\hline E1-E3 & $864(35.5)$ & $650(33.9)$ & $214(41.6)$ & \\
\hline E4-E6 & $1291(53.1)$ & $1038(54.1)$ & $253(49.2)$ & \\
\hline E7-E9, W1-W5, 01-09 & $278(11.4)$ & $231(12.0)$ & $47(9.1)$ & \\
\hline Years in the military $(n=2388)$ & & & & $<0.01$ \\
\hline 0 & $55(2.3)$ & $42(2.2)$ & $13(2.6)$ & \\
\hline 1 & 466 (19.5) & $340(18.1)$ & $126(25.0)$ & \\
\hline $2-3$ & $775(32.5)$ & $584(31.0)$ & $191(37.9)$ & \\
\hline $4+$ & $1092(45.7)$ & $918(48.7)$ & $174(34.5)$ & \\
\hline Mean $\pm S D$, median & $5.5 \pm 5.6,3$ & $5.9 \pm 5.9,3$ & $4.1 \pm 4.3,3$ & $<0.01$ \\
\hline Range & $0-36$ & $0-36$ & $0-23$ & \\
\hline Number of official deployments completed $(n=2358)$ & & & & $<0.01$ \\
\hline 0 & $546(23.2)$ & $395(21.3)$ & $151(30.2)$ & \\
\hline 1 & $783(33.2)$ & $580(31.2)$ & $203(40.6)$ & \\
\hline $2+$ & $1029(43.6)$ & $883(47.5)$ & $146(29.2)$ & \\
\hline Mean $\pm S D$, median & $2.1 \pm 2.5,1$ & $2.3 \pm 2.6,1$ & $1.3 \pm 1.4,1$ & $<0.01$ \\
\hline Range & $0-20$ & $0-20$ & $0-10$ & \\
\hline Race/ethnicity $(n=2407)$ & & & & $<0.01$ \\
\hline White & $1276(53.0)$ & $1055(55.6)$ & $221(43.3)$ & \\
\hline Black or African American & $309(12.8)$ & $215(11.3)$ & $94(18.4)$ & \\
\hline Filipino & $132(5.5)$ & $106(5.6)$ & $26(5.1)$ & \\
\hline American Indian or Alaska Native & $20(0.8)$ & $14(0.7)$ & $6(1.2)$ & \\
\hline Asian & $73(3.0)$ & $58(3.1)$ & $15(2.9)$ & \\
\hline Native Hawaiian or Pacific Islander & $18(0.8)$ & $10(0.5)$ & $8(1.6)$ & \\
\hline Spanish/ Hispanic/Latino & $358(14.9)$ & $275(14.5)$ & $83(16.3)$ & \\
\hline Other & $41(1.7)$ & $32(1.7)$ & $9(1.8)$ & \\
\hline Two or more races/ethnicities & $180(7.5)$ & $132(7.0)$ & $48(9.4)$ & \\
\hline Marital status $(n=2451)$ & & & & $<0.01$ \\
\hline Single, never married, not in committed relationship & $748(30.5)$ & $588(30.4)$ & $160(31.1)$ & \\
\hline Single, in committed relationship, living with partner & $541(22.1)$ & $361(18.7)$ & $180(35.0)$ & \\
\hline Married & $996(40.6)$ & $875(45.2)$ & $121(23.5)$ & \\
\hline Divorced, separated or widowed & $166(6.8)$ & $112(5.8)$ & $54(10.5)$ & \\
\hline Education level completed $(n=2426)$ & & & & $<0.01$ \\
\hline$\leq$ High school, GED & $1030(42.5)$ & $863(45.0)$ & $167(32.8)$ & \\
\hline Some college, vocational/tech school (non-military) & $1031(42.5)$ & $779(40.7)$ & $252(49.4)$ & \\
\hline ZUndergraduate degree & 365 (15.1) & $274(14.3)$ & $91(17.8)$ & \\
\hline Tattoo, or piercing/injection, past 12 months $(\mathrm{n}=2309$ ) & & & & $<0.01$ \\
\hline Tattoo(s) reported & $731(31.7)$ & $517(28.6)$ & $214(43.0)$ & \\
\hline Piercing and/or injection reported & $88(3.8)$ & $58(3.2)$ & $30(6.0)$ & \\
\hline No & $1490(64.5)$ & $1236(68.3)$ & $254(51.0)$ & \\
\hline
\end{tabular}

E, enlisted rank; GED, general equivalency diploma; 0, officer rank; W, warrant officer rank.

home port, assessing sexual behaviour history in the preceding 12 months; (2) deployment, within the last 4 weeks of deployment, assessing sexual behaviour while underway; and (3) postdeployment, within 3 months after return from deployment, assessing sexual behaviour since return. Data reported in the current analysis are from the predeployment survey. This 
study protocol and procedures were approved by the Naval Health Research Center Institutional Review Board (NHRC.2010.0033) and Walter Reed Army Institute of Research Human Subjects Protection Branch (WRAIR \#1766).

\section{Inclusion criteria}

Military personnel were eligible for study inclusion if they were active duty, attached to a participating ship within the US Third Fleet area of responsibility and available to participate during

Table 2 Sexual partner type and sexual behaviours among active-duty deploying US Navy and Marine Corps respondents by sex

\begin{tabular}{|c|c|c|c|c|c|c|c|}
\hline \multirow[b]{2}{*}{ Characteristic } & \multicolumn{2}{|l|}{ Total } & \multicolumn{2}{|l|}{ Men } & \multicolumn{2}{|c|}{ Women } & \multirow[b]{2}{*}{ p Value } \\
\hline & $\mathrm{N}$ & $\%$ & $\mathbf{N}$ & $\%$ & $\mathrm{~N}$ & $\%$ & \\
\hline Partner type at last sex* $(n=1896)$ & & & & & & & $<0.01$ \\
\hline Spouse & 931 & 49.1 & 811 & 54.5 & 120 & 29.5 & \\
\hline Regular, non-spouse & 619 & 32.7 & 387 & 26.0 & 232 & 57.0 & \\
\hline Occasional & 183 & 9.7 & 144 & 9.7 & 39 & 9.6 & \\
\hline One-night stand, not a sex worker & 141 & 7.4 & 129 & 8.7 & 12 & 3.0 & \\
\hline Sex worker & 11 & 0.6 & 11 & 0.7 & 0 & 0.0 & \\
\hline Other & 11 & 0.6 & 7 & 0.5 & 4 & 0.9 & \\
\hline Service member sex contact partner typet ( $n=446$ ) & & & & & & & $<0.01$ \\
\hline Spouse & 115 & 25.8 & 66 & 33.7 & 49 & 19.6 & \\
\hline Regular, non-spouse & 236 & 52.9 & 74 & 37.8 & 162 & 64.8 & \\
\hline Occasional & 60 & 13.5 & 31 & 15.8 & 29 & 11.6 & \\
\hline One-night stand, not a sex worker & 31 & 7.0 & 23 & 11.7 & 8 & 3.2 & \\
\hline Sex worker & 2 & 0.5 & 2 & 1.0 & 0 & 0.0 & \\
\hline Other & 2 & 0.5 & 0 & 0.0 & 2 & 0.8 & \\
\hline Location where participant meets new, casual or temporary sex partners $(n=2335)$ & & & & & & & $\ddagger$ \\
\hline Work & 384 & 16.5 & 270 & 14.7 & 114 & 23.0 & \\
\hline Through friends, family & 661 & 28.3 & 529 & 28.8 & 132 & 26.6 & \\
\hline Bars, club, restaurant, coffee house & 563 & 24.1 & 517 & 28.1 & 46 & 9.3 & \\
\hline Internet & 229 & 9.8 & 214 & 11.6 & 15 & 3.0 & \\
\hline Sporting events & 108 & 4.6 & 103 & 5.6 & 5 & 1.0 & \\
\hline School & 201 & 8.6 & 163 & 8.9 & 38 & 7.7 & \\
\hline Other & 44 & 1.9 & 39 & 2.1 & 5 & 1.0 & \\
\hline Not applicable, don't seek partners & 1345 & 57.6 & 1044 & 56.8 & 301 & 60.7 & \\
\hline Sex acts engaged in, past 12 months§ & & & & & & & $\neq$ \\
\hline \multicolumn{8}{|l|}{ Opposite sex $(n=1904)$} \\
\hline Oral sex & 1584 & 88.8 & 1316 & 89.6 & 268 & 85.4 & \\
\hline Vaginal sex & 1729 & 97.0 & 1428 & 97.2 & 301 & 95.9 & \\
\hline Participant was the anal insertive partner & 331 & 18.6 & 325 & 22.1 & 6 & 1.9 & \\
\hline Participant was the anal receptive partner & 83 & 4.7 & 16 & 1.1 & 67 & 21.3 & \\
\hline \multicolumn{8}{|l|}{ Same sex $(n=93)$} \\
\hline Oral sex & 74 & 83.2 & 34 & 75.6 & 40 & 90.9 & \\
\hline Vaginal sex & 3 & 74.2 & NA & NA & 36 & 81.8 & \\
\hline Participant was the anal insertive partner & 22 & 24.7 & 17 & 37.8 & 5 & 11.4 & \\
\hline Participant was the anal receptive partner & 18 & 20.2 & 11 & 24.4 & 7 & 15.9 & \\
\hline \multicolumn{8}{|l|}{ Bisexual sex $(n=79)$} \\
\hline Oral sex & 69 & 94.5 & 31 & 88.6 & 38 & 100.0 & \\
\hline Vaginal sex & 61 & 83.6 & 28 & 80.0 & 33 & 86.8 & \\
\hline Participant was the anal insertive partner & 23 & 31.5 & 21 & 60.0 & 2 & 5.3 & \\
\hline Participant was the anal receptive partner & 18 & 24.7 & 14 & 40.0 & 4 & 10.5 & \\
\hline Engaged in quick anal sex, 9 past 3 months $(n=2202)$ & 240 & 10.9 & 194 & 11.2 & 46 & 9.8 & 0.39 \\
\hline \multicolumn{8}{|l|}{ Total partners, past 12 months $(n=1650)$} \\
\hline Mean $\pm S D$, median & \multicolumn{2}{|c|}{$3.9 \pm 15.2,1$} & \multicolumn{2}{|c|}{$3.9 \pm 15.2,1$} & \multicolumn{2}{|c|}{$3.8 \pm 15.3,1$} & 0.14 \\
\hline Range & \multicolumn{2}{|c|}{$1-340$} & \multicolumn{2}{|c|}{$1-340$} & \multicolumn{2}{|c|}{$1-210$} & \\
\hline $\begin{array}{l}\text { Among those with sexual relationship outside their main relationship, } \\
\text { number of outside partners, past } 12 \text { months }(n=395)\end{array}$ & & & & & & & $<0.01$ \\
\hline 1 outside partner & 210 & 53.2 & 151 & 48.9 & 59 & 68.6 & \\
\hline $2-3$ outside partners & 120 & 30.4 & 99 & 32.0 & 21 & 24.4 & \\
\hline $4+$ outside partners & 65 & 16.5 & 59 & 19.1 & 6 & 7.0 & \\
\hline Engaged in group sex, past 3 months $(n=2105)$ & 119 & 5.4 & 111 & 6.3 & 8 & 1.7 & $<0.01$ \\
\hline Engaged in transactional sex, past 12 months $(n=2229)$ & 83 & 3.7 & 79 & 4.5 & 4 & 0.8 & $<0.01$ \\
\hline Frequency participant drank alcohol before sex, past 12 months $(n=2359)$ & & & & & & & 0.02 \\
\hline
\end{tabular}


Table 2 Continued

\begin{tabular}{|c|c|c|c|c|c|c|c|}
\hline \multirow[b]{2}{*}{ Characteristic } & \multicolumn{2}{|l|}{ Total } & \multicolumn{2}{|l|}{ Men } & \multicolumn{2}{|c|}{ Women } & \multirow[b]{2}{*}{ p Value } \\
\hline & $\mathbf{N}$ & $\%$ & $\mathrm{~N}$ & $\%$ & $\mathrm{~N}$ & $\%$ & \\
\hline Rarely & 548 & 23.2 & 419 & 22.6 & 129 & 25.7 & \\
\hline Occasionally & 881 & 37.4 & 705 & 38.0 & 176 & 35.0 & \\
\hline Always, typically & 162 & 6.9 & 139 & 7.5 & 23 & 4.6 & \\
\hline Don't know/remember & 43 & 1.8 & 38 & 2.1 & 5 & 1.0 & \\
\hline Did not drink alcohol before sex in the past 12 months & 725 & 30.7 & 555 & 29.9 & 170 & 33.8 & \\
\hline Prescription/non-prescription drugs used to enhance sex, past 12 months, Yes ( $n=2351$ ) & 375 & 16.0 & 309 & 16.7 & 66 & 13.2 & 0.05 \\
\hline \multicolumn{8}{|c|}{$\begin{array}{l}\text { *Respondents who marked 'Not applicable, I never had sex' or reported two or more sex partners at last sex were excluded from the denominator. } \\
\text { †Among respondents who reported their most recent sexual encounter was with a service member }(\mathrm{n}=446) \text {, participants also identified what type of partner that service member w } \\
\text { (eg, spouse service member partner, occasional service member partner). Among those with service member partners at most recent sexual encounter, the proportion of each partn } \\
\text { type within that subgroup is reported here. } \\
\text { †Variables are not mutually exclusive. } \\
\text { §Within each of these classifications, the proportion was calculated from respondents who reported that specific type of sex (eg, oral) divided by the total number of people who } \\
\text { reported any type of sex within the past } 12 \text { months, among only those respondents within that classification (eg, same sex, opposite sex). } \\
\text { IqDefined as anal sex where the participant or his/her partner only inserted the penis briefly. }\end{array}$} \\
\hline
\end{tabular}

survey administration. Aircraft carriers, destroyers, amphibious assault ships, landing ship docks and amphibious transport docks were included as platforms for study participation. Permission to survey personnel was obtained from US Third Fleet and ship commanding officers.

\section{Data collection tool}

The survey collected information on basic demographics (eg, age, marital status, education, rank, service branch, deployment history), history of healthcare provider-diagnosed STIs, sexual risk behaviours, condom use, alcohol use (measured by an abbreviated version of the Alcohol Use Disorders Identification Test, drinks per week/day/occasion, binge drinking and Cut down, Annoyed, Guilty, Eye-opener (CAGE) alcohol assessments), drug use, symptoms of mental health disorders (measured using the Center for Epidemiologic Studies Depression Scale and the posttraumatic stress disorders (PTSD) ChecklistCivilian Version) and recent stressful life events.

Marital status classifications 'Single, in a committed relationship, but not living with a partner' and 'Single, living with a partner' were collapsed for analysis. Respondents were instructed to mark 'Single, living with a partner' if they normally reside with their sexual partner but were currently deployed or stationed away, and 'Separated' if they were no longer in a committed relationship with their spouse but not yet legally divorced (not temporarily separated due to deployment).

Respondents were determined to have an STI if they reported that a doctor or other health professional had told them they had gonorrhoea, chlamydia, trichomoniasis, syphilis, herpes, hepatitis B, genital warts, anal warts, pubic lice (crabs) and/or other STIs/conditions in the past 12 months.

Transactional sex was defined as sex that was provided or received for money, goods (eg, gifts, free drinks, drugs, housing) and/or improved work conditions or assignments. Respondents provided information on whether their sexual partner was male and/or female and were classified into mutually exclusive categories of having only same-sex partners, only opposite-sex partners, or both. Respondents provided information on partner type (eg, spouse, regular, occasional, etc) the last time they had sex and whether this partner was a service member. An outside (not main) sexual relationship was defined as oral, vaginal and/or anal sex with anyone other than the respondent's reported spouse, regular, committed partner or live-in partner. See online supplementary material for additional information on study variables.

\section{Data analysis}

To detect a significant association between the exposure of interest and outcome $(0.01 \alpha$ level, 95\% power), the target sample size was 5480 participants. Data were analysed using SAS software, V.9.2 (SAS Institute, Cary, North Carolina, USA). Descriptive statistics were calculated for all continuous variables and percentages for categorical variables. Reported values were excluded if they were logically inconsistent or impossible. All other missing responses were excluded from the denominator for each individual variable. Two-sample $\mathrm{T}$ tests for continuous variables and Pearson's $\chi^{2}$ tests for categorical variables (or Fisher's exact test where expected count was less than 5) were used to assess whether there was a significant difference for each independent variable by sex. Where categories were not mutually exclusive (ie, type of sex engaged in, where respondents met sexual partners), $\mathrm{p}$ values were not calculated and proportions were reported. All $\mathrm{p}$ values were based on two-tailed tests

Table 3 Pathogen-specific proportion of self-reported doctor-diagnosed sexually transmitted infections (STIs) among active-duty deploying US Navy and Marine Corps respondents reporting $\geq 1$ STI in the past 12 months by sex

\begin{tabular}{|c|c|c|c|c|c|c|}
\hline \multirow[b]{2}{*}{ Characteristic* } & \multicolumn{2}{|c|}{ Total } & \multicolumn{2}{|c|}{ Men } & \multicolumn{2}{|c|}{ Women } \\
\hline & $\mathrm{N}$ & $\begin{array}{l}\text { Per } \\
\text { cent }\end{array}$ & $\mathbf{n}$ & $\begin{array}{l}\text { Per } \\
\text { cent }\end{array}$ & $\mathbf{n}$ & $\begin{array}{l}\text { Per } \\
\text { cent }\end{array}$ \\
\hline Overall, $\geq 1$ STI reported & 58 & 2.4 & 32 & 1.7 & 26 & 5.1 \\
\hline Chlamydia only & 30 & 51.7 & 16 & 50.0 & 14 & 53.8 \\
\hline $\begin{array}{l}\text { Chlamydia and gonorrhoea } \\
\text { only }\end{array}$ & 1 & 1.7 & 0 & 0.0 & 1 & 3.8 \\
\hline $\begin{array}{l}\text { Chlamydia, gonorrhoea and } \\
\geq 1 \text { other STI }\end{array}$ & 7 & 12.1 & 7 & 21.9 & 0 & 0.0 \\
\hline Chlamydia and $\geq 1$ other STI† & 2 & 3.4 & 2 & 6.3 & 0 & 0.0 \\
\hline Gonorrhoea only & 2 & 3.4 & 1 & 3.1 & 1 & 3.8 \\
\hline Gonorrhoea and $\geq 1$ other STI‡ & 3 & 5.2 & 3 & 9.4 & 0 & 0.0 \\
\hline Herpes only & 4 & 6.9 & 0 & 0.0 & 4 & 15.4 \\
\hline Herpes and $\geq 1$ STIst‡ & 1 & 1.7 & 1 & 3.1 & 0 & 0.0 \\
\hline Anogenital warts only & 6 & 10.3 & 2 & 6.3 & 4 & 15.4 \\
\hline$\geq 1$ other STI§ & 2 & 3.4 & 0 & 0.0 & 2 & 7.7 \\
\hline
\end{tabular}

*Variables are mutually exclusive.

tExcluding gonorrhoea.

¥Excluding chlamydia.

§Excluding any STI (s) reported in other categories. 
of significance, defined as $\mathrm{p} \leq 0.05$. $\mathrm{p}$ Values were not adjusted for multiple comparisons.

\section{RESULTS}

Logistical and administrative requirements of accessing our study population during combat operations was time intensive requiring over 2 years to collect data on all three time points among the 11 ships. We chose to stop recruitment prior to reaching our original enrolment because a recalculation of study power suggested a smaller study population would achieve adequate power, and it was important to disseminate this information in a timely manner. All ships approached by study personnel agreed to participate, with the exception of one ship slated for decommissioning. Of the 2806 surveys collected, 2593 (92\%) respondents aboard 11 ships completed the predeployment survey (primarily within the 1 st week of deployment). The proportion of completed surveys ranged from $84 \%$ to $98 \%$ with more incomplete surveys reported among destroyer platforms. Those not reporting either gender $(n=17)$ and/or age $(n=123)$ were excluded (final $n=2453$, men=1938, women $=515)$.

\section{Participant characteristics}

Overall, the study population median age was 24 years, with nearly half $(46.8 \%)$ between the ages of 20 years and 24 years (table 1$)$ and $21 \%(\mathrm{n}=515 / 2453)$ female. The majority $(83.9 \%)$ was US Navy and enlisted (88.6\%). Just over half of respondents were on their first or second official deployment and had been in the military for 3 years or less. All demographic factors differed significantly by sex $(\mathrm{p} \leq 0.05)$. A higher proportion of men were aged 30 years or older $(27.4 \%$ vs $16.9 \%)$ and married $(45.2 \%$ vs $23.5 \%)$ than women.

In total, $67 \%(n=1262 / 1896)$ of all respondents reported their most recent sexual encounter was with either a spouse $(n=931)$ or non-spouse service member $(n=331$, table 2$)$. A fourth of respondents $(24.8 \%, n=446 / 1800)$ reported their most recent sexual partner was also a service member. A higher proportion of women than men $(78.9 \%, \mathrm{n}=321 / 407$ vs $63.2 \%$, $\mathrm{n}=941 / 1489$ ) reported a spouse or non-spouse service member as their most recent sexual encounter.

Among respondents who reported they had an outside sexual relationship $(n=395), 53 \%$ reported 1 outside partner, 30\% reported 2 or 3 , and $17 \%$ reported 4 or more. Among those who reported an outside sexual relationship, 30\% $(n=72 / 243)$ reported their last sexual encounter was with a service member.

\section{STIs and condom use}

Overall, 2156 participants reported no history of an STI (81\% of women, $n=411 / 505$ and $92 \%$ of men, $n=1745 / 1896)$. Within the past 12 months, $2.4 \%$ of service members $(n=58 /$ 2401) reported a physician or healthcare professional told them they had one or more STIs, with the majority of those $(68.9 \%$, $n=40 / 58$ ) reporting chlamydia alone or in combination with one or more other STIs (table 3, also see online supplementary material). Significantly $(\mathrm{p}<0.01)$ higher proportions of women than men reported diagnosis with chlamydia, gonorrhoea and/ or trichomoniasis $(3.4 \%, \mathrm{n}=17 / 505$ vs $1.5 \%, \mathrm{n}=29 / 1896)$ or chlamydia, gonorrhoea, trichomoniasis, syphilis, herpes and/or hepatitis $\mathrm{B}$ in the past 12 months $(4.2 \%, \mathrm{n}=21 / 505$ vs $1.6 \%$, $\mathrm{n}=30 / 1896)$. Among men, $1.4 \%(\mathrm{n}=25)$ reported a burning discharge from their penis in the past 3 months, similar to the proportion $(1.5 \%)$ who reported physician-diagnosed chlamydia, gonorrhoea or trichomoniasis in the past 12 months.

Overall, about a fourth of all respondents $(26.3 \%, \mathrm{n}=582)$ reported using a condom the last time they had sex. Among men and women who reported on condom use and had an outside sexual relationship, only 24.1\% $(n=90 / 373)$ used a condom the last time they had sex.

\section{STI acquisition variables}

Among respondents reporting a location $(n=234)$ where they believed they acquired their most recent STI $(20 \%$ of whom reported an STI in the previous 12 months), 90\% ( $n=210 / 233)$ reported acquiring their last STI in the USA (table 4). A significantly larger proportion of women reported their STI was acquired from a service member than did men (50\% vs $25.8 \%$, $\mathrm{p}<0.01)$. Among respondents who reported $\geq$ one deployments and a physician diagnosed STI $\geq 1$ year ago, $88 \%(n=126 / 143)$ reported acquiring their STI within the USA.

\section{DISCUSSION}

\section{Principal findings}

Among shipboard US active-duty Navy and Marine Corps personnel, $67 \%$ of most recent sexual partners were either service members or military beneficiaries (among women only, this increased to almost 80\%). Few personnel in concurrent

Table 4 Sexually transmitted infection (STI) acquisition location and partner type among active-duty deploying US Navy and Marine Corps respondents by sex*

\begin{tabular}{|c|c|c|c|c|c|c|c|}
\hline \multirow[b]{2}{*}{ Characteristic } & \multicolumn{2}{|c|}{ Total } & \multicolumn{2}{|l|}{ Men } & \multicolumn{2}{|c|}{ Women } & \multirow[b]{2}{*}{ p Value } \\
\hline & $\mathbf{N}$ & Per cent & n & Per cent & $\mathbf{n}$ & Per cent & \\
\hline Where infected with last STI $(n=233)$ & & & & & & & 0.04 \\
\hline Within USA & 210 & 90.1 & 128 & 87.1 & 82 & 95.4 & \\
\hline Outside USA & 23 & 9.9 & 19 & 12.9 & 4 & 4.7 & \\
\hline Type of partner acquired STI from $(n=287)$ & & & & & & & $<0.01$ \\
\hline Spouse & 39 & 13.6 & 22 & 11.7 & 17 & 17.2 & \\
\hline Regular & 92 & 32.1 & 39 & 20.7 & 53 & 53.5 & \\
\hline Occasional & 46 & 16.0 & 32 & 17.0 & 14 & 14.1 & \\
\hline One-night stand (not a sex worker) & 64 & 22.3 & 57 & 30.3 & 7 & 7.1 & \\
\hline Sex worker & 20 & 7.0 & 17 & 9.0 & 3 & 3.0 & \\
\hline Don't know & 26 & 9.1 & 21 & 11.2 & 5 & 5.1 & \\
\hline STI acquired from service member $(n=298)$ & 101 & 33.9 & 51 & 25.8 & 50 & 50.0 & $<0.01$ \\
\hline
\end{tabular}


partnerships reported condom use at last sex. Most STIs were acquired within the USA with many acquired from spouses or regular partners.

\section{Strengths and weaknesses}

Data were collected directly from shipboard military personnel prior to, during and immediately after deployment, which is operationally challenging and rarely attempted. Other US military STI data are generally acquired from electronic health record databases ${ }^{1}{ }^{12}$ or from large standardised US military health surveys that contain few questions on sexual risk behaviour. $^{5} 613$ Other more comprehensive studies have been typically confined to a specific subpopulation, are less recent and/or were not designed to assess behaviour specifically across deployment cycles. ${ }^{78}$ We are unaware of any comparable sexual behaviour data on male and female service members as that collected in the current study. Study findings will therefore be discussed in context with studies most closely resembling data presented herein, while noting such comparisons are imprecise.

Data from shipboard US Navy and Marine Corps active-duty service members at predeployment may not be generalisable to personnel from other service branches; however, information assessed captured behaviour over the prior 12 months while personnel were primarily shore-based and likely comparable to other shore-based service members. Data were obtained through convenience sampling; however, survey administration was conducted at various times to optimise recruiting a representative sample of service members from most departments and across a variety of ship platforms. All measures collected in this survey were self-reported and subject to recall bias, but the time period assessed (limited to the past 12 months), may have reduced the likelihood of this. Several questions were of a highly sensitive nature, and some questions had a larger proportion of nonresponse than others. For example, illicit drug use is prohibited by the Uniform Code of Military Justice, and respondents may have been reluctant in disclosing such information despite the anonymous data collection. Additionally, this study showed a larger proportion of women than men reported a healthcare provider-diagnosed STI in the past 12 months (primarily chlamydia); however, data are self-reported (not based on biological STI testing) so it is possible, study prevalence does not capture asymptomatic infection. However, a detection bias is unlikely to account for the higher prevalence observed among women, since military and civilian population-based studies show higher chlamydia prevalence among women, even when universal screening occurs. ${ }^{14}$ Furthermore, data collected in a crosssectional manner cannot capture time-dependent trends. This limitation should be addressed with data from additional time points.

\section{Comparison with other studies}

The last published shipboard assessment of STI risk, conducted nearly 20 years ago among an all-male crew, showed sex worker contact (before and during deployment) in foreign ports as a primary factor associated with STIs, ${ }^{8}$ which continues to be the prevailing concept to date. ${ }^{15} 16$ The current study shifts the focus of STI acquisition among male shipboard sailors from sex workers to predominantly regular sexual partners within the local military community (not foreign port or liberty stops). Almost no service members reported their most recent sexual encounter was with a sex worker and few respondents believed their last STI was acquired from one. Nearly one-fifth of personnel reportedly met their sexual partners at the workplace. Half of women (and a quarter of men) acquired their last STI from another service member, and over half of the female respondents believed they acquired their STI from a spouse or regular partner (many of whom were service members). Nearly all $(90 \%)$ of service members acquired their last STI within the USA, even after excluding those without prior deployment. This shift in partner type and location may enable more successful partner referral for treatment programmes. ${ }^{17}$

Concurrent partnerships within this study population were frequent. Previous studies show concurrent sexual partnerships as a risk factor for STI transmission, ${ }^{18}$ so overlapping concurrent partnerships may increase STI transmission within the military setting. Unlike data collected from the 2008 Department of Defense (DoD) Health Related Behaviours Survey ${ }^{6}$ which showed a larger proportion of men than women with outside sexual partners $(37.1 \%$ vs $17.5 \%)$, the current study found that equal proportions of men and women (17.3\% vs $17.6 \%)$ reported outside sexual partners (although men more frequently reported three+ partners). The Health Related Behaviours Survey population differs from the current study population in that it was not designed to assess service members' health at deployment onset, and only includes service members who are not currently deployed. These differences may reflect different sexual practices among men scheduled to deploy and those assigned to shore-based duty stations, but additional information is needed to adjust for other confounding factors.

The chlamydia prevalence reported here is consistent with estimates $(1.7 \%$, 95\% CI $1.4 \%$ to $2.0 \%)$ determined by biological STI testing reported in a recent US population-based study $^{14} 19$ and US Navy and Marine Corps population-based screening study, ${ }^{20}$ supporting the validity of our data and suggesting similarity to shore-based military personnel and civilian prevalence.

\section{Implications}

With substantial proportions of service members reporting sex with a spouse and/or other service members, structural interventions should be implemented to educate service members on safer sex behaviours and STI reduction and should be sexspecific and extended to military beneficiaries. Contact tracing, screening and treatment of sexual partners may be more feasible given that the target population is largely composed of other service members or beneficiaries with full coverage by the military healthcare system. Even treatment of at least the index case may contribute to reduced STI prevalence within the entire military network since many sexual contacts may be other service members and beneficiaries.

Approximately 20\% of women (with an opposite-sex partner) and $24 \%$ of men (with a same-sex partner) are reportedly engaging in anal receptive sex. Efforts to educate female and male service members and their beneficiaries on the increased HIV transmission risk through anal sex compared with vaginal sex, ${ }^{21}$ and guidance on proper condom use (ie, lubricant needs to be used with condoms during anal sex) may protect service members from STIs.

Leadership messages encouraging condom use should be sexspecific, given the variations in regular and casual partnerships, types of sexual contact, number of outside sexual partners and differences in STI-associated morbidity by sex. Given that only a quarter of respondents with multiple sexual partners reported using a condom at last sex, STI reduction interventions within the shipboard US military population should emphasise consistent condom use with all sexual partners among nonmonogamous service members and more frequent STI screening. 


\section{Future research}

Women comprise approximately 17\% of the US Navy (and 21\% of this study population), with men outnumbering women by about 5 to 1. Data collected from US civilian population-based studies and individuals seeking care at STI clinics show higher proportions of concurrent partnerships in populations where the sex ratio is unbalanced ${ }^{2-24}$ and unbalanced sex ratios may have an impact on STI transmission. ${ }^{23}$ Future studies should examine these social and structural factors which may influence STI risk.

Previous data have shown characteristics of sexual and social network contacts can impact an individual's STI acquisition and transmission risk and the ability to engage in safer sex behaviours. $^{25-27} \mathrm{~A}$ better understanding of the sexual network among shipboard personnel about to deploy (which may extend to shore-based service members) is needed since effective interventions will vary based on partner selection patterns, demographic and social factors and predominant pathogen (ie, chlamydia in the current study) within the sexual network. 25262829

\section{Key messages}

- The majority (67\%) of US shipboard personnel reported last sex with a military beneficiary (either a spouse or non-spouse service member).

- Only $24 \%$ of shipboard personnel who reported having one or more sex partners outside their primary sexual relationship used a condom at last sex.

- The majority (90\%) of most recent sexually transmitted infections (STIS) were acquired within the USA.

- More women than men (50\% vs $26 \%$ ) reported their most recent STI was acquired from another service member.

\author{
Author affiliations \\ ${ }^{1}$ US Military HIV Research Program, Walter Reed Army Institute of Research, Silver \\ Spring, Maryland, USA \\ ${ }^{2}$ Henry M. Jackson Foundation for the Advancement of Military Medicine, Bethesda, \\ Maryland, USA \\ ${ }^{3}$ Department of Defense HIVIAIDS Prevention Program (DHAPP), Naval Health \\ Research Center, San Diego, California, USA \\ ${ }^{4}$ Third Fleet, US Navy, San Diego, California, USA \\ ${ }^{5}$ Division of Infectious Diseases, Department of Medicine, University of California \\ School of Medicine, San Diego, California, USA
}

\section{Handling editor Jackie A Cassell}

\section{Twitter Follow Michael Wolf at @michael8078}

Acknowledgements The authors thank the US Third Fleet for the opportunity to collect data and for their support of this study.

Contributors $\mathrm{JH}$ collaborated on study design, acquisition of data, analysis and interpretation of data, drafted the manuscript, and provided critical revision of the manuscript. PTS and BRH collaborated on study design, acquisition of data, interpretation of the data, and critically revised the manuscript. JMoo, JMor, ST and MW collaborated on study design and acquisition of data, and provided critical review of the manuscript. JT provided statistical coding and data editing needed for the statistical analysis, collaborated on drafting the methods section of the manuscript and reviewed the manuscript. MD'O assisted with data acquisition, interpretation of the data and review of the manuscript. MPG, BRT, MBJ, SII and JM provided input into study design, data acquisition and critical review of the manuscript. NM collaborated on study design, interpretation of the data and critical revision of the manuscript.

Funding This work was supported by a cooperative agreement (W81XWH-07-20067) between the Henry M Jackson Foundation for the Advancement of Military Medicine, Inc., and the US Department of Defense work unit 60546.
Disclaimer The views expressed are those of the authors, and do not necessarily reflect the official policy or position of the Department of the Navy, Department of the Army, Department of Defense or the US Government. Approved for public release; distribution is unlimited. US Government Work (17 USC 105).

Competing interests None declared.

Ethics approval Naval Health Research Center and Walter Reed Army Institute of Research.

Provenance and peer review Not commissioned; externally peer reviewed.

Data sharing statement Additional analyses and publication drafts are in development.

Open Access This is an Open Access article distributed in accordance with the Creative Commons Attribution Non Commercial (CC BY-NC 4.0) license, which permits others to distribute, remix, adapt, build upon this work non-commercially, and license their derivative works on different terms, provided the original work is properly cited and the use is non-commercial. See: http://creativecommons.org/ licenses/by-nc/4.0/

\section{REFERENCES}

1 Armed Forces Health Surveillance Center. Sexually transmitted infections, active component, U.S. Armed Forces, 2000-2012. MSMR 2013;20:5-10.

2 Armed Forces Health Surveillance Center. Pelvic inflammatory disease among female recruit trainees, active component, U.S. Armed Forces, 2002-2012. MSMR 2013:20:15-18

3 Gaydos JC, McKee KT, Gaydos CA. The changing landscape of controlling sexually transmitted infections in the U.S. military. MSMR 2013;20:2-4.

4 Armed Forces Health Surveillance Center. Reportable medical events, active and reserve components, U.S. Armed Forces, 2009. MSMR 2010;17:22-8.

5 Barlas FM, Higgins WB, Pflieger JC, et al. 2011 Department of Defense Health Related Behaviours Survey of Active Duty Military Personnel. 2013. http://www. murray.senate.gov/public/_cache/files/889efd07-2475-40ee-b3b0-508947957a0f/ final-2011-hrb-active-duty-survey-report.pdf (accessed Mar 2015).

6 Stahlman S, Javanbakht M, Cochran S, et al. Self-reported sexually transmitted infections and sexual risk behaviours in the U.S. military: how sex influences risk. Sex Transm Dis 2014:41:359-64.

7 Boyer CB, Pollack LM, Becnel J, et al. Relationships among sociodemographic markers, behavioural risk, and sexually transmitted infections in U.S. female Marine Corps recruits. Mil Med 2008;173:1078-84.

8 Malone JD, Hyams KC, Hawkins RE, et al. Risk factors for sexually-transmitted diseases among deployed U.S. military personnel. Sex Transm Dis 1993;20:294-8.

9 Statement by the President on the repeal of Don't Ask, Don't Tell. 20 September 2011. http://www.whitehouse.gov/the-press-office/2011/09/20/ statement-president-repeal-dont-ask-dont-tell (accessed Dec 2014).

10 Katz KA. Health hazards of "Don't Ask, Don't Tell". N Engl J Med 2010;363:2380-1.

11 Bull SS, McFarlane M. Soliciting sex on the Internet: what are the risks for sexually transmitted diseases and HIV? Sex Transm Dis 2000;27:545-50.

12 Sena AC, Miller WC, Hoffman IF, et al. Trends of gonorrhea and chlamydial infection during 1985-1996 among active-duty soldiers at a United States Army installation. Clin Infect Dis 2000;30:742-8.

13 Stahlman S, Javanbakht M, Cochran S, et al. A comparison of self-reported sexual risk behaviours between US civilian and active duty military women. Sex Health. Published Online First: 7 Apr 2015. doi:10.1071/SH14211

14 Torrone E, Papp J, Weinstock H. Prevalence of Chlamydia trachomatis genital infection among persons aged 14-39 years-United States, 2007-2012. MMWR Morb Mortal Wkly Rep 2014;63:834-8.

15 Boyer CE, Shafer MB, Shaffer RA, et al. Prevention of sexually transmitted diseases and HIV in young military men. Sex Transm Dis 2001;28:349-55.

16 MacDonald M. Doc- can we talk? The conscience check and the Navy healthcare provider. 2013. http://navymedicine.navylive.dodlive.mil/archives/5871 (accessed Aug 2015).

17 van de Laar MJ, Termorshuizen F, van den Hoek A. Partner referral by patients with gonorrhea and chlamydial infection. Case-finding observations. Sex Transm Dis 1997;24:334-42.

18 Gorbach PM, Drumright LN, Holmes KK. Discord, discordance, and concurrency: comparing individual and partnership-level analyses of new partnerships of young adults at risk of sexually transmitted infections. Sex Transm Dis 2005;32:7-12.

19 Datta SD, Torrone E, Kruszon-Moran D, et al. Chlamydia trachomatis trends in the United States among persons 14 to 39 years of age, 1999-2008. Sex Transm Dis 2012;39:92-6.

20 Harbertson J, Scott P, Graf P, et al. Randomized, Active-duty U.S. military population-based NAAT screening for asymptomatic Neisseria gonorrhoeae, Chlamydia trachomatis, and Trichomonas vaginalis infection using de-identified urine samples received by the Navy Drug Screening Laboratory, San Diego. ID Week 2014; Philadelphia, PA, 2014

21 Patel P, Borkowf CB, Brooks JT, et al. Estimating per-act HIV transmission risk: a systematic review. AIDS 2014;28:1509-19. 
22 Adimora AA, Schoenbach VJ, Taylor EM, et al. Sex ratio, poverty, and concurrent partnerships among men and women in the United States: a multilevel analysis. Ann Epidemiol 2013;23:716-19.

23 Pouget ER, Kershaw TS, Niccolai LM, et al. Associations of sex ratios and male incarceration rates with multiple opposite-sex partners: potential social determinants of HIV/STI transmission. Public Health Rep 2010;125(Suppl 4):70-80.

24 Senn TE, Carey MP, Vanable PA, et al. The male-to-female ratio and multiple sexual partners: multilevel analysis with patients from an STD clinic. AIDS Behav 2010;14:942-8.

25 De $P$, Singh $A E$, Wong $T$, et al. Sexual network analysis of a gonorrhoea outbreak. Sex Transm Infect 2004;80:280-5.
26 Laumann EO, Youm Y. Racial/ethnic group differences in the prevalence of sexually transmitted diseases in the United States: a network explanation. Sex Transm Dis 1999;26:250-61.

27 Morris M, Zavisca J, Dean L. Social and sexual networks: their role in the spread of HIVIAIDS among young gay men. AIDS Educ Prev 1995;7(Suppl 5): 24-35.

28 Aral SO. Sexual network patterns as determinants of STD rates: paradigm shift in the behavioural epidemiology of STDs made visible. Sex Transm Dis 1999;26:262-4

29 Youm Y, Laumann EO. Social network effects on the transmission of sexually transmitted diseases. Sex Transm Dis 2002;29:689-97. 